\title{
CAMOQUIN IN THE TREATMENT OF ACUTE LEPRA REACTION
}

\author{
R. H. ThangaraJ, M.B., B.S. \\ Medical Officer, Purulia Leprosy Home and Hospital, \\ Purulia, West Bengal
}

When I was medical officer at Schieffelin Sanatorium, Karagiri, I treated 45 lepromatous patients for acute lepra reaction in three groups of 15 patients. One group was kept as a control, and the others were put on potassium antimony tartrate or camoquin, each patient being placed in one of the three groups by drawing lots. Only cases with fever, erythema nodosum, or subcutaneous nodules were selected for the study. All cases had been under treatment with DDS, sulphetrone, or thiosemicarbazone, and the blood had been examined for malaria.

Thus in the potassium antimony tartrate group, 13 were on DDS, one on thiosemicarbazone, one on sulphetrone. In the camoquin group, eleven were on DDS, two on thiosemicarbazone, and two on sulphetrone. In the control group, 14 were on DDS and one on thiosemicarbazone.

In the potassium antimony tartrate group, this drug was given intravenously on alternate days, with an initial dose of $0.02 \mathrm{gm}$. gradually increasing to $0.05 \mathrm{gm}$. In the camoquin group the initial dose was three tablets, then one tablet twice a day for four days. Camoquin of Parke Davis \& Co., Ltd. contains 0.25 gm. per tablet of amodiaquine hydrochloride.

\section{Results}

In the potassium antimony tartrate group the reaction subsided in five patients after four days, in six patients after six to eight days, in three patients after nine to twelve days, in one patient only after cortisone was used.

In the camoquin group, four cases had subsidence of the reaction on the second day after camoquin was begun, four cases after the third day of camoquin, three cases after the fourth day, two cases after the fifth, and the remaining two cases did not respond to the camoquin after six days of it and potassium antimony tartrate was then used and the reaction subsided after four days more.

In the control group, in three patients the reaction subsided after four days, in six patients after five to eight days, and in the remaining six cases potassium antimony tartrate or cortisone had eventually to be used to control the reaction. 


\section{Summary}

Camoquin is effective in the control of acute lepra reaction in lepromatous leprosy at an initial dosage of three tablets by mouth, followed by two tablets daily for four days. In one case only the camoquin was given for six days and in that case it failed. In this and in one other case in which camoquin failed, subsequent use of potassium antimony tartrate was successful.

Compared with a group on potassium antimony tartrate, camoquin achieves its effect in less time. In an untreated group, nine out of fifteen cases became free of the reaction spontaneously in four to eight days.

\section{References}

Susman, I. A., Clinical Observations on Erythema Nodosum Leprosum. Leprosy Review 29, 4: Oct. 1958, pp. 227-228.

Casals, D. A. Camoquin in Acute Lepra Reaction. Revista de Sifil. Leprol. y Dermatol. Cuba 13th year, No. 1, 1957, pp. 19-21. 